\title{
Uma nova espécie de Mezilaurus Taubert (Lauraceae) para a flora brasileira
}

\author{
Flávio Macedo Alves ${ }^{1}$ e João Batista Baitello²
}

Recebido em 31/10/2006. Aceito em 18/06/2007

\begin{abstract}
RESUMO - (Uma nova espécie de Mezilaurus Taubert (Lauraceae) para a flora brasileira). É descrita e ilustrada uma nova espécie de Mezilaurus Taubert (Lauraceae): Mezilaurus vanderwerffii F.M. Alves \& J.B. Baitello, caracterizada por folhas densamente dotadas de pontoações glandulares na face adaxial. A espécie é relatada para o Cerrado, Cerradão, e Floresta Estacional Semidecidual do entorno do Pantanal Matogrossense.
\end{abstract}

Palavras-chave: nova espécie, Mezilaurus, Lauraceae, Mato Grosso do Sul, Brasil

\begin{abstract}
A new species of the genus Mezilaurus Taubert (Lauraceae) for the brazilian flora). The species was named Mezilaurus vanderwerffii F.M. Alves \& J.B. Baitello and is characterized by leaves with dense, glandular dots on the adaxial surface. The species is reported for Cerrado, Cerradão, and Semideciduous Forest surrounding the Pantanal Matogrossense
\end{abstract}

Key words: new species, Mezilaurus, Lauraceae, Mato Grosso do Sul, Brasil

\section{Introdução}

Os inventários botânicos têm revelado que Lauraceae está, em termos florísticos e econômicos, entre as famílias mais importantes, mas a identificação de suas espécies é tarefa difícil (Baitello 2001). A maioria dos seus gêneros não pode ser distinguida seguramente com base apenas em caracteres vegetativos (Rohwer 1993b). Por esta razão é essencial, para uma identificação segura, a presença de flores, pois, em geral, as chaves de identificação e as descrições taxonômicas estão baseadas em caracteres florais (van der Werff 1991).

O gênero Mezilaurus Taubert compreende 18 espécies, ocorrendo da Costa Rica ao Sudeste do Brasil. A maioria das espécies é encontrada em áreas de boa drenagem do rio Amazonas e poucas espécies ocorrem em outros ecossistemas (van der Werff 1987).

Mezilaurus é um dos gêneros de Lauraceae que possuem as menores flores, cerca de $2 \mathrm{~mm}$ de diâmetro na antese, caracteriza-se por folhas, em geral, congestas no ápice dos ramos, flores trímeras, bissexuadas, apenas 3 estames férteis, representando a série III, e cúpula pouco desenvolvida, quase sempre estreita e em forma de um disco plano.

O gênero é pobremente coletado e, por esta razão, a maioria das coleções botânicas possui poucos espécimens, o que demonstra a necessidade de maior número de coletas para melhorar o entendimento taxonômico do gênero (van der Werff 1987).

Estudo florístico da família Lauraceae no Mato Grosso do Sul revelou uma nova espécie de Mezilaurus, representando a segunda espécie do gênero para o Bioma Cerrado (lato sensu) da região Centro-Oeste, embora as coletas disponíveis revelem que esta espécie não é exclusiva desse Bioma.

\section{Material e métodos}

Este estudo foi realizado atravéz de consulta aos herbários CGMS (Herbário da UFMS, Campo Grande, MS), COR (Herbário da UFMS, Corumbá, MS), UB (Herbário da UNB, Brasília, DF) e SPSF (Herbário do Instituto Florestal do Estado de São Paulo), HPL (Instituto Plantarum de Estudos da Flora Ltda).

\footnotetext{
1 Universidade de São Paulo, Instituto de Biociências, Av. Pádua Dias 11, C. Postal 09, 13418-900 Piracicaba, SP, Brasil

2 Instituto Florestal, Rua do Horto 931, 02377-000 Bairro Horto Florestal, São Paulo, SP, Brasil (baitello@if.sp.gov.br)

3 Autor para correspondência: flaurace@yahoo.com.br
} 


\section{Resultados e discussão}

Mezilaurus vanderwerffii F.M. Alves \& J.B. Baitello sp. nov.

Fig. 1a-b

A Mezilaurus crassiramea et $M$. itauba floribus glabris, foliis adaxialiter confertim et minime pontoadoglandulosis differt.
Árvore até $16 \mathrm{~m}$; râmulos crassos, lenticelados, glabrescentes ou glabros, cicatrizes foliares evidentes; gema apical densamente alvo-serícea. Folhas congestas no ápice dos ramos; lâmina cartácea, levemente discolor, sub-brilhante em ambas as faces, 6,0-17,0×4,0-6,0 cm, elíptica a obovada, decorrente para o pecíolo, ápice agudo a sub-obtuso, base aguda, densamente e minutamente pontoado-glandulosa,

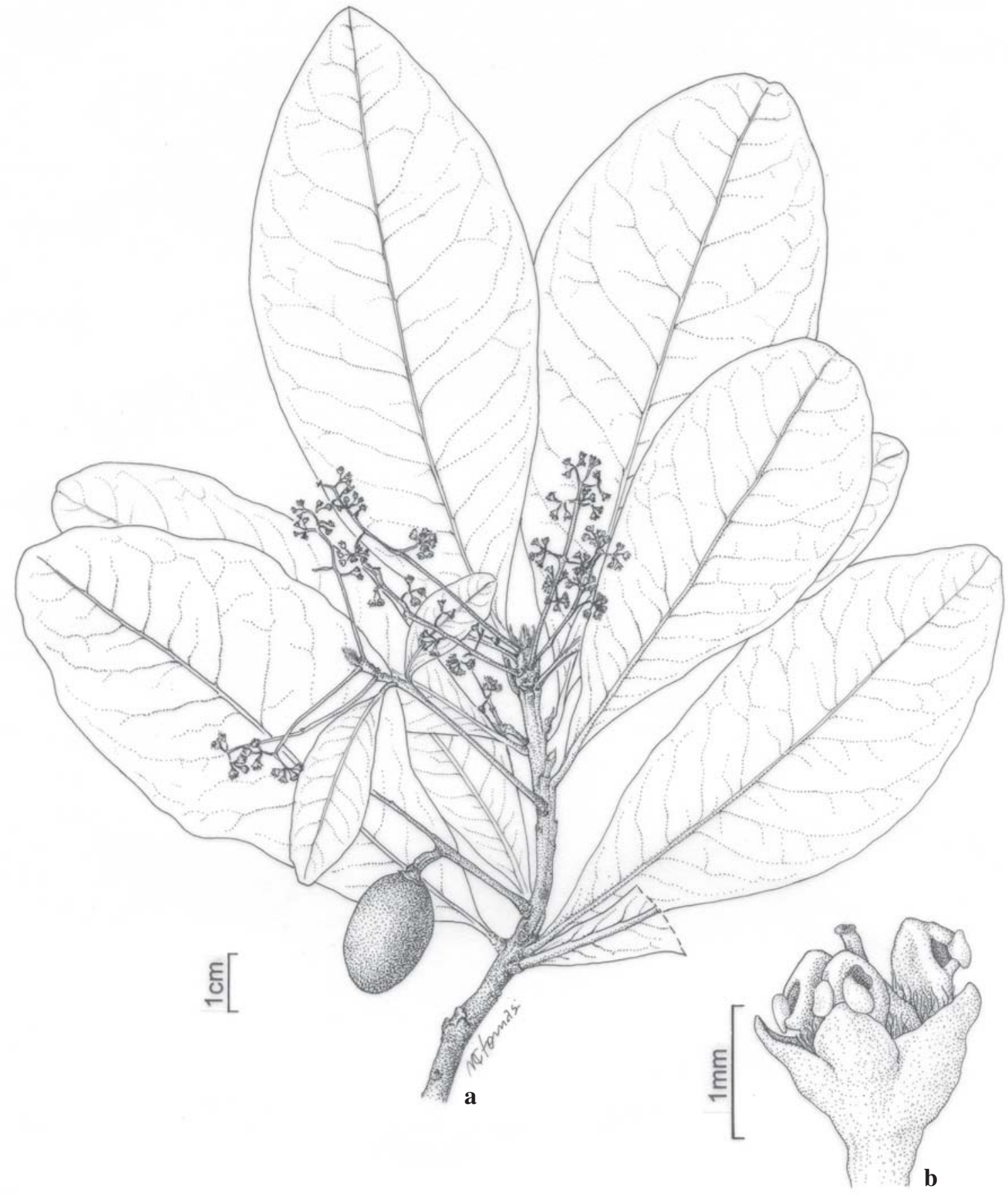

Figura 1. Mezilaurus vanderwerffii F.M. Alves \& J.B. Baitello (H. Lorenzi 1467): a. Ramo com frutos. b. Flor com os três únicos estames (série III). 
pontoações visíveis sob lupa na face adaxial, e sob luz forte, como pontos translúcidos, em ambas as faces, face adaxial glabra, abaxial esparsamente pubescente a glabra, venação eucamptódroma, nervura central na face abaxial achatada na base, saliente e mais estreita para o ápice, nervuras laterais $10-14$ pares. Pecíolo achatado, 2,0-4,5 mm compr., esparso e curtamente pubescente, pêlos eretos.

Inflorescência subterminal, axilar, agrupada no ápice dos ramos, mais curtas que as folhas, flores aglomeradas no ápice dos ramos laterais, ramos esparso-pubescentes a glabros, pêlos curtos, pedúnculo até $3,5 \mathrm{~cm}$. Flores ca. 2,0×2,0 mm, glabras externamente; tubo floral obcônico, pouco profundo, densamente pubescente por dentro; pedicelo 1,3-3,0 mm; tépalas 6, subiguais, ca. 1,0×1,0 mm, eretas, mais curtas que o tubo floral, face interna densamente pubescente na base, pêlos longos, quase apressos, margem papilosa. Estames 3, representados pela série III, todos férteis, sem glândulas, exsertos na antese, ca. $1,0 \times 0,6 \mathrm{~mm}$, anteras glabras, ligeiramente dolabriformes, locelos 2, apicais, amplos, lateral-extrosos, filetes livres, pouco mais estreitos que as anteras, densamente pubescentes, pêlos longos e levemente crespos; estaminódios quando presentes, podendo ser apenas 1 , bem a pouco desenvolvidos, ápice piramidal, filódio densamente pubescente, pêlos longos; pistilo lageniforme, glabro, 1,5×0,7 mm, ovário elípsóide, atenuado para o curto estilete, estigma subcapitado. Fruto $2,0 \times 1,5 \mathrm{~cm}$, elipsóide, verde quando jovem, negro quando plenamente maduro, pedúnculo curto, lenhoso; cúpula subpateliforme, estreita, 4,0-6,0 mm larg., tépalas persistentes ou caducas.

Tipo: BRASIL. Mato Grosso do Sul: Ribas do Rio Pardo, 3/IV/1994, fl., fr., H. Lorenzi, H. 1467. (Holótipo SPSF; Isótipo HPL).

Parátipos: BRASIL. Mato Grosso do Sul: Aquidauana, Estrada do Paxixi, Morro do Paxixi, 26/X/1986, bot., S.T. Vasconcellos et al. 34 (COR, UB); Aquidauana, Piraputanga, 2/IV/1994, fl., fr., H. Lorenzi 1495 (HPL), Aquidauana, Piraputanga, Pesqueiro da Serra, 11/XI/1997, fl., U.M. Resende 1032 (CGMS); Ribas do Rio Pardo, margem da rodovia MS 262, 28/IX/1994, fr., G.F. Arbocz 792 (SPSF).

Distribuição geográfica: a espécie é freqüentemente encontrada no Cerradão de Piraputanga e no Morro do Paxixi, município de Aquidauana, no Cerrado típico e na Floresta Estacional Semidecidual do entorno do Pantanal Matogrossense. Lorenzi (1998), refere que a espécie apresenta freqüência elevada, porém dispersão muito descontínua ao longo da sua área de distribuição.

Comentários: a principal característica diagnóstica da espécie é a presença de pontoações glandulares, vistas sob luz forte como pontos translúcidos através das faces adaxial e abaxial, caráter não encontrado em nenhuma outra espécie do gênero. Mezilaurus vanderwerffii enquadra-se no grupo de espécies cujas flores são glabras, pediceladas e de anteras biloceladas (van der Werff 1987). Até o presente esta nova espécie e Mezilaurus crassiramea (Meisn.) Taubert ex Mez, são as únicas que têm ocorrência no Cerrado, porém, ambas são perfeitamente distintas, pois, Mezilaurus crassiramea possui folhas com ambas as faces pubescentes, flores e ramos puberulentos, enquanto que Mezilaurus vanderwerffii tem folhas com a face adaxial densamente pontoado-glandulosa, face abaxial glabrescente, flores externamente glabras e ramos com poucos tricomas esparsos.

O epíteto homenageia Henk van der Werff, do Missouri Botanical Garden (USA), grande estudioso da família Lauraceae e autor da última revisão do gênero.

A madeira de Mezilaurus vanderwerffiii, por ser dura e pesada, é utilizada localmente para moirões, postes, cruzetas, dormentes, carpintaria em geral, armações de pontes, obras hidráulicas e outras obras externas que requeiram resistência mecânica e grande durabilidade (Lorenzi 1998). Seus frutos são apreciados pela avifauna, especialmente por tucanos.

$\mathrm{Na}$ sua região de ocorrência é conhecida como tapinhoã, nome dado para outra espécie do gênero, Mezilaurus navalium (Allemão) Taubert ex Mez, que ocorre na mata atlântica do Estado do Rio de Janeiro.

\section{Agradecimentos}

À MSc. Ubirazilda Maria Resende, pelas valiosas informações sobre a ecologia e utilização econômica da espécie; a Jefferson Prado, do Instituto de Botânica, pela diagnose latina, às curadoras dos Herbários CGMS, Ângela Lúcia Bagnatori Sartori e COR, Iria Hiromi Ishii, pelo apoio logístico; à Conservation International (CI-Brasil), pela bolsa de Mestrado de Flávio Macedo Alves.

\section{Referências bibliográficas}

Baitello, J.B. 2001. Novas Espécies de Lauraceae para a Flora Brasileira. Acta Botanica Brasilica 15: 445-450. 
Lorenzi, H. 1998. Árvores brasileiras. Manual de identificação e cultivo de plantas arbóreas do Brasil. v.2. Nova Odessa, Editora Plantarum.

Rohwer, J.G. 1993a. Lauraceae. Pp. 366-391. In: K. Kubitzki; J.G. Rohwer \& V. Bittrich (eds.). The Families and Genera of Vascular Plants. Flowering Plants. Dicotyledons. Berlin, Springer-Verlag,
Rohwer, J.G. 1993b. Lauraceae: Nectandra. Flora Neotropica, Monograph 60. New York, New York Botanical Garden. van der Werff, H. 1987. A Revision of Mezilaurus (Lauraceae). Annals of the Missouri Botanical Garden 74: $153-182$

van der Werff, H. 1991. A Key to the Genera of Lauraceae in the New World. Annals of the Missouri Botanical Garden 78: 377-387. 